\title{
Field test and evaluation on crop dividers of sugarcane chopper harvester
}

\author{
Jing Bai, Shaochun Ma*, Fenglei Wang, Haonan Xing, Jinzhi Ma, Jiwei Hu \\ (Beijing Key Laboratory of Optimized Design for Modern Agricultural Equipment, College of Engineering, \\ China Agricultural University, Beijing 100083, China)
}

\begin{abstract}
In South China, the tropical weather and climate result in severe sugarcane lodging problems which greatly hinders sugarcane mechanical harvesting. The main function of the crop divider is to lift lodged canes and facilitate base-cut cane feeding. In this study, a series of field tests were conducted on crop dividers of Liugong 4GQ-180 sugarcane chopper harvester. The tests were designed to identify the relationships of the performance index (maximum lifting height of sugarcane) and the main influencing factors (machine forward speed, rotational speed of inside scrolls, and ground clearance of crop divider toes). The single factor test was conducted to determine optimum range of these test factors: the forward speed (FS) was 2.0-4.0 km/h, the rotational speed of inside scrolls (RS) was 100-140 $\mathrm{r} / \mathrm{min}$, and the toe ground clearance (GC) was $0-5 \mathrm{~cm}$. The orthogonal test (three factors and three levels) was carried out to determine the optimal combination of operating parameters: FS was $2.0 \mathrm{~km} / \mathrm{h}$, RS was $115 \mathrm{r} / \mathrm{min}$, and GC was $0 \mathrm{~cm}$. In addition, the range analysis of orthogonal test results revealed that the order of each test factor affecting crop divider performance was RS, FS, GC. This study was expected to provide valuable references for the optimal operation of sugarcane harvester crop dividers.
\end{abstract}

Keywords: sugarcane chopper harvester, parameter optimization, machine forward speed, rotational speed of scrolls, ground clearance, maximum lifting height, field test, evaluation, crop divider

DOI: $10.25165 /$ j.ijabe.20211401.5621

Citation: Bai J, Ma S C, Wang F L, Xing H N, Ma J Z, Hu J W. Field test and evaluation on crop dividers of sugarcane chopper harvester. Int J Agric \& Biol Eng, 2021; 14(1): 118-122.

\section{Introduction}

Sugarcane is an important cash crop in China and plays an important role in national life. In recent years, the planting area of sugarcane has decreased year by year due to labor scarcity and the increasing cost, which has a negative effect on the development of sugar industry in China ${ }^{[1,2]}$. However, the level of sugarcane mechanical harvesting in China is still very low. Harvesting is a crucial component of sugarcane production system. Therefore, it is of great significance to develop sugarcane harvesters in China ${ }^{[3,4]}$. Generally, a typical sugarcane chopper harvester consists of a topper, two crop dividers, a base cutter, a feeding mechanism, a conveying device, a chopper, and extractors ${ }^{[5,6]}$. At present, there are mainly two kinds of crop dividers: spiral crop dividers and finger-chain crop dividers. Because of good adaptability, spiral crop dividers are widely used in harvesters. Each spiral crop divider normally includes two spiral scrolls (inside scrolls and outside scrolls, Figure 1). During harvesting, the inside scrolls rotate to lift and center lodged canes using installed spiral flights. Outside scrolls rotate in the opposite direction of inside scrolls to separate the adjacent cane rows away.

Thus, the crop divider is a crucial component of the sugarcane

Received date: $2019-12-30 \quad$ Accepted date: $2020-12-01$

Biographies: Jing Bai, PhD candidate, research interest: sugarcane harvesting technology, Email: 2459350357@qq.com; Fenglei Wang, PhD candidate, research interest: sugarcane harvesting technology, Email: 1577863616@qq.com; Haonan Xing, PhD candidate, research interest: sugarcane harvesting technology, Email: 449286363@qq.com; Jinzhi Ma, Master candidate, research interest: sugarcane harvesting technology, Email: 1303049058@qq.com; Jiwei Hu, Master candidate, research interest: sugarcane harvesting technology, Email: 459621854@qq.com.

*Corresponding author: Shaochun $\mathrm{Ma}, \mathrm{PhD}$, Associate Professor, research interest: apple and sugarcane harvesting technology and equipment. College of Engineering, China Agricultural University, Beijing 100080, China. Tel: +86-10-62736638, Email: shaochun2004@qq.com. chopper harvester, in the literature, various techniques have been studied. Based on the dynamic simulation, Song et al. designed a two-section spiral crop divider and major parameters were studied through experimental tests with high speed photograph technology. However, the transition problem between the picking and conveying mechanism was not solved ${ }^{[7]}$. Additionally, they also developed a two-section spiral picking mechanism and carried out virtual experiments and mechanical analyses to study its performance ${ }^{[8,9]}$. Xie et al. ${ }^{[10]}$ conducted a kinematic analysis of a combined crop divider in which the basic equation describing the sugarcane lifting process was deduced to study the relationship between main operating parameters. Xie et al. ${ }^{[1]}$ designed a combined crop divider and analyzed the lifting process through the field test, which showed that the lifting rate of severely lodged cane could reach $90 \%$. Gao et al. ${ }^{[12]}$ carried out the theoretical study and virtual prototype simulation on crop dividers. Based on this study, the theoretical model of the crop divider-sugarcane interacting process was established in this research. To harvest severely lodged sugarcane, Zhang et al. ${ }^{[13]}$ designed a finger-chain crop divider and studied the influencing rule of critical factors (installation angle, the angle between crop divider and the forward direction, rotational speed of crop divider, and machine forward speed) through the virtual orthogonal test. Dong et al. ${ }^{[14]}$ firstly installed variable pitch spiral flights on crop divider scrolls. During harvesting, the spiral angle on the scrolls increased gradually from the cone bottom to the top which made lodged canes keep good contact with the scrolls.

In South China, sugarcane planting is greatly affected by monsoon and typhoon causing sugarcane to lodged or sprawled on the ground ${ }^{[15-17]}$. During harvesting, severe lodged canes often slip from the spiral flights or are totally missed, or even pushed down directly by crop dividers. At present, there are still many issues with crop dividers that cannot effectively lift lodged canes. 
In the harvesting process, the parameter settings on crop dividers are extremely important for their lifting performance. In this study, the performance test of crop dividers of Liugong 4GQ-180 sugarcane chopper harvester was carried out to determine the optimal settings. The effects of different forward speeds of harvester (FS), the rotational speed of crop divider inside scrolls (RS), and the ground clearance of crop divider toes (GC) on the maximum lifting height of sugarcane stalk were analyzed. This study could provide valuable references improving performance of the crop dividers.

\section{Materials and methods}

\subsection{Materials preparation}

The experiment was carried out in March 2019 at China Agricultural University Professor Workstation which was located in Quli Town, Fusui County, Chongzuo City, Guangxi Zhuang Autonomous Region, China. The lifting performance of crop dividers of the 4GQ-180 sugarcane chopper harvester (Liugong Machinery Co., Ltd, Liuzhou, Guangxi, China) was explored in this study. The physical conditions of sugarcane and test field were shown in Table 1. Figure 1 shows the field test crop dividers which consist of inside scrolls, outside scrolls, crop divider toes, and floating sidewalls.

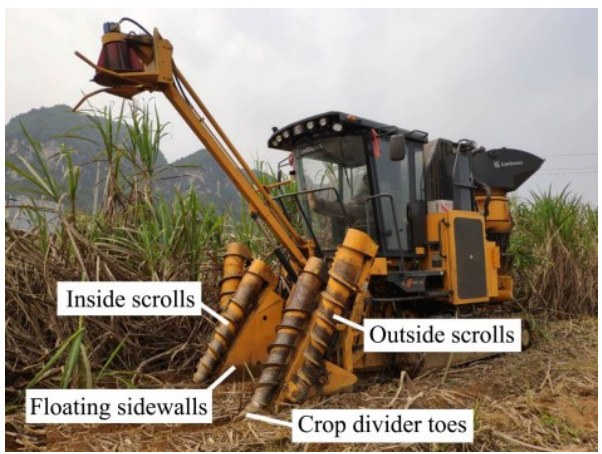

Figure 1 Crop dividers of sugarcane chopper harvester

Table 1 Sugarcane and field conditions

\begin{tabular}{ccccc}
\hline Variety & Ridge/m & $\begin{array}{c}\text { Soil solidity } \\
/ \mathrm{kPa}\end{array}$ & $\begin{array}{c}\text { Soil moisture } \\
\text { content } / \%\end{array}$ & $\begin{array}{c}\text { Lodging levels of } \\
\text { lodged canes } / \%\end{array}$ \\
\hline Guitang 43 & 1.2 & $1928.66 \pm 17.32$ & 25.36 & $60 \pm 4.5$ \\
\hline \multicolumn{7}{l}{ Note: the data represents mean \pm standard deviation }
\end{tabular}

Before the experiment, the sugarcane field which had $60 \%$ of canes lodged was selected, and the actual situation of test field (the ridge, the length of test area) was measured. The measurement zones were selected randomly. Sugarcane stalks were labeled with numbers. The side angle and lodging angle of sugarcane were measured by the digital level (LS1601l digital display level instrument, Guangdong, China). The staff gauge was placed in an appropriate position in front of the harvester, as shown in Figure 2. During the test, the lifting height of the lodged canes was aligned with the scale, so that the maximum lifting height was measured. The high-speed camera (FR-Stream USB Camera of Guangzhou Yuanao Instrument Co., Ltd, Guangdong, China) was used to record the lifting process. TroublePix $\times 64$ software (NorPix, Inc., Quebec, Canada) was installed on the computer. The processor of the computer is Intel Core i5, and the operating system is Microsoft Windows 10 Professional $\times 64$ with 8 GB RAM. The field test was conducted according to sugarcane harvesting machinery test method JB/T6275-2007 based on the People's Republic of China Machinery Industry Standard ${ }^{[18]}$.

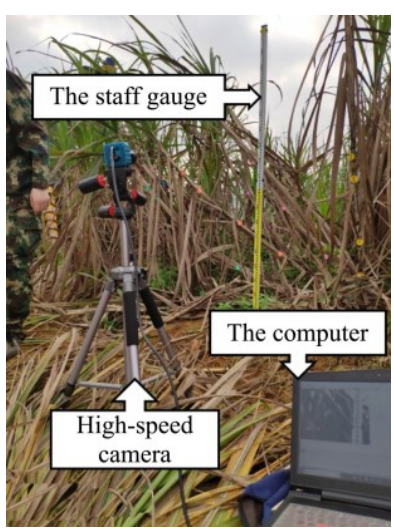

Figure 2 Settings of equipment for lifting height measurement

\subsection{Experimental factors and indicators}

According to pre-tests and previous studies ${ }^{[19]}$, the lifting performance of crop dividers depends on the settings of operation parameters. The forward speed, rotational speed of inside scrolls, and toe ground clearance were selected as three main factors on the lifting performance for this experiment and the maximum lifting height of sugarcane stalks was selected as the evaluation indicator.

During the test, the forward speed was mainly controlled by the harvester operator, the rotational speed of inside scrolls was adjusted via controlling hydraulic motors, and the toe ground clearance was also controlled by hydraulic cylinders, as shown in Figure 3.

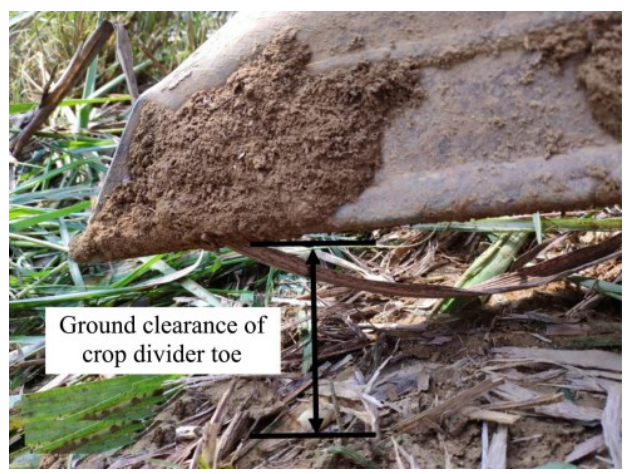

Figure 3 Ground clearance of crop divider toe

The Cartesian coordinate system was established, and a schematic diagram of the sugarcane lifting process was shown in Figure $4^{[20]}$. Among them, $\alpha$ was the angle between the centerline of sugarcane stalk and the plumb line, defined as the lodging angle; $\beta$ was the angle between the inside scroll and horizontal plane, defined as the installation angle of crop dividers; $\gamma$ was the angle between the stalk vertical projection and the forward direction of the harvester, defined as the side angle; $k$ was the contact point between the lodged sugarcane and the inside scroll; and $h$ was the vertical distance from ground to contact point $k$, defined as the lifting height of the crop divider to the lodged sugarcane. When the contact point $k$ gradually moved to the highest point, the lifting height $h$ reached the maximum value, which was called the maximum lifting height $h_{m}$.

In this study, the lifting height of sugarcane was calculated according to Equation (1).

$$
h=h_{1}-h_{2}
$$

where, $h$ is the absolute lifting height of lodged canes, $\mathrm{cm} ; h_{1}$ is the reading of staff gauge when sugarcane was at the highest contact point between cane stalk and the crop divider, $\mathrm{cm} ; h_{2}$ was the reading of staff gauge on the ground, $\mathrm{cm}$. 


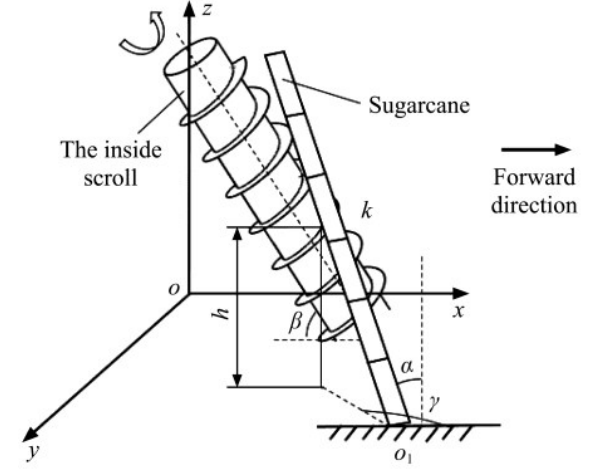

$\alpha$ : Lodging angle of sugarcane, $\left({ }^{\circ}\right) ; \beta$ : Installation angle of the crop divider, $\left(^{\circ}\right) ; \gamma$ : Side angle of sugarcane, $\left({ }^{\circ}\right) ; k$ : Contact point between sugarcane and inside scroll; $h$ : Lifting height of sugarcane, $\mathrm{cm}$

Figure 4 Schematic diagram of the sugarcane lifting process

\subsection{Experimental design}

In the experiment, the forward speed (FS), the rotational speed of inside scrolls (RS), and the toe ground clearance (GC) were selected as the experiment factors and the maximum lifting height was set as the evaluation indicator. To examine the effects of experimental factors on evaluation indicator, the single factor experiment and orthogonal experiment were carried out.

For the single factor experiment, different levels of experimental factors are shown in Table 2. During the experiment, the levels of two factors were fixed, and the other factor was set as a variable. After setting up the equipment in the harvester, the recorded parameters for factors were used to investigate corresponding maximum lifting height.

Table 2 Setting of factor levels for single factor experiment

\begin{tabular}{lcccccccc}
\hline \multirow{2}{*}{ Factors } & \multicolumn{7}{c}{ Levels } \\
\cline { 2 - 9 } & 1 & 2 & 3 & 4 & 5 & 6 & 7 & 8 \\
\hline $\mathrm{FS} / \mathrm{km} \cdot \mathrm{h}^{-1}$ & 0.5 & 1.0 & 1.5 & 2.0 & 2.5 & 3.0 & 3.5 & 4.0 \\
$\mathrm{RS} / \mathrm{r} \cdot \mathrm{min}^{-1}$ & 80 & 90 & 100 & 110 & 120 & 130 & 140 & 150 \\
$\mathrm{GC} / \mathrm{cm}$ & 0 & 2 & 4 & 6 & 8 & 10 & 12 & 14 \\
\hline
\end{tabular}

Based on the field experiments, when the lodging angle was less than $60^{\circ}$, the lifting effect of the crop divider was improved. When the side angle was less than $45^{\circ}$ or greater than $135^{\circ}$, it was difficult for the lodged sugarcane to be lifted. Therefore, sugarcanes with the lodging angle of about $60^{\circ}$ and the side angle of about $45^{\circ}$ and $135^{\circ}$ were selected as test samples. To minimize test errors, each treatment was repeated five times, and the results were averaged.

To determine the optimal combination of operation parameters of crop dividers, the effect of each parameter on evaluation indicator was studied, and the orthogonal test was carried out. The forward speed (A), the rotational speed of inside scrolls (B) and the toe ground clearance $(\mathrm{C})$ were selected as three factors on the lifting performance for this experiment. And the maximum lifting height of sugarcane stalks was selected as the evaluation indicator. Similar to the single factor test, each group was repeated five times, and the values were averaged to minimize test errors. The setting of experimental factor levels was shown in Table 3.

Table 3 Factor levels of the orthogonal test

\begin{tabular}{cccc}
\hline \multirow{2}{*}{ Levels } & \multicolumn{3}{c}{ Factors } \\
\cline { 2 - 4 } & $\mathrm{A} / \mathrm{km} \cdot \mathrm{h}^{-1}$ & $\mathrm{~B} / \mathrm{r} \cdot \mathrm{min}^{-1}$ & $\mathrm{C} / \mathrm{cm}$ \\
\hline 1 & 2 & 100 & 0 \\
2 & 3 & 115 & 2.5 \\
3 & 4 & 130 & 5.0 \\
\hline
\end{tabular}

\section{Results and discussion}

\subsection{Single factor test}

The single factor test results of the forward speed of harvester are shown in Figure 5. The rotational speed of inside scrolls was $110 \mathrm{r} / \mathrm{min}$, and the toe ground clearance was $6 \mathrm{~cm}$. It showed that with the increasing forward speed, the maximum lifting height of the lodged sugarcane increased sharply first, and then increased slowly to be flat. The reason for the above trend was that the forward speed was required to match the corresponding rotational speed. When the forward speed was too low, the lifting efficiency was quite poor. When the forward speed of the harvester was higher, the lodged sugarcane was gradually raised with the spiral flights as the spiral scroll rotated, and the lifting effect was improved. However, with the lodged sugarcane being lifted to a certain height, the maximum lifting height increased slowly. The reason was that the cane stalk and spiral scroll had surface contact at the beginning of lifting process (lower position), however, the surface contact became point contact when the cane stalk was lifted to a certain height. Under point contacting, cane stalk can easily slip from the spiral scrolls. The fixed pitch of the spiral scroll is difficult to adapt to the increasing lodging angles. In addition, when the forward speed was too fast, the maximum lifting height began to decline because the sugarcane could be easily pushed away by the crop dividers, or even crushed down by harvester wheels, resulting in harvesting losses. In the range of the forward speed of 2.0-4.0 km/h, the crop divider behaved a good lifting performance in terms of the maximum lifting height.

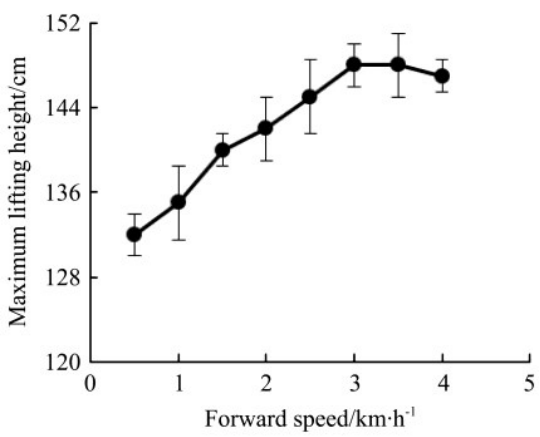

Note: RS was $110 \mathrm{r} / \mathrm{min}$; GC was $6 \mathrm{~cm}$.

Figure 5 Relationship between the forward speed and maximum lifting height

The single factor test results of the rotational speed of inside scrolls were shown in Figure 6. The forward speed was $2 \mathrm{~km} / \mathrm{h}$, and the toe ground clearance was $6 \mathrm{~cm}$. As the rotational speed of inside scrolls increased, the maximum lifting height of the lodged sugarcane stalks increased continuously, however, the increasing rate gradually became slower. The main reason was that in the early stage of lifting, the contact area between sugarcane stalk and the spiral scroll was relatively larger. Thus, when the rotational speed of the inside scroll was higher, the lodged sugarcane could be fed without being pushed down. And sugarcane was gradually raised along with the spiral flights, and the lifting effect behaved better. However, with the sugarcane being lifted, the lodging angle of sugarcane decreased continuously, the contact area between sugarcane stalk and the spiral scroll decreased which caused cane stalks to easily slip from the spiral scroll and the maximum lifting height increased slowly. When the rotational speed was too high, the lifting process would become unstable causing cane stalks to easily jump or slip off the spiral scroll. When the scroll rotational speed ranged 100-140 r/min, the maximum lifting height of lodged sugarcane had satisfying values. 


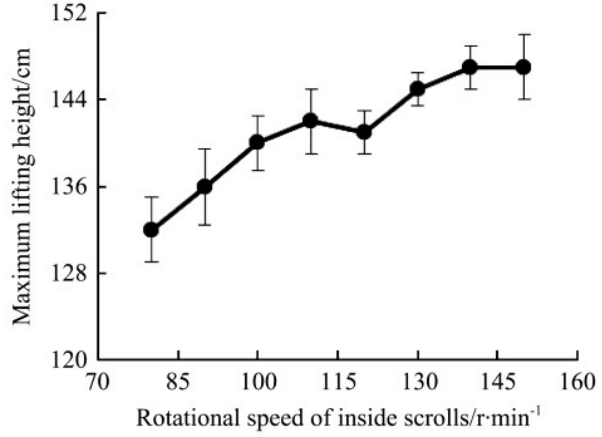

Note: FS was $2 \mathrm{~km} / \mathrm{h}$; GC was $6 \mathrm{~cm}$.

Figure 6 Relationship between the rotational speed of inside scrolls and maximum lifting height

The single factor test results of the toe ground clearance were shown in Figure 7. The forward speed was $2 \mathrm{~km} / \mathrm{h}$, and the rotational speed of inside scrolls was $110 \mathrm{r} / \mathrm{min}$. From the analysis of Figure 7, it can be seen that the maximum lifting height of cane stalks declined with increasing ground clearance of crop divider toe. The reason was that the higher ground clearance made it more difficult for the crop divider toe to contact with ground surface. As a result, many sugarcane stalks with larger lodging angle cannot be lifted, thus, the lifting effect became worse. However, when the toe ground clearance was $0 \mathrm{~cm}$, the crop divider clung to the ground, which can help the lodged sugarcane be lifted efficiently. When harvesting, the crop divider was set to cling to the ground by an operator, obstacles could be removed with sharp toes in the field. Within the range of $0-5 \mathrm{~cm}$, the lifting effect can be improved to an acceptable level.

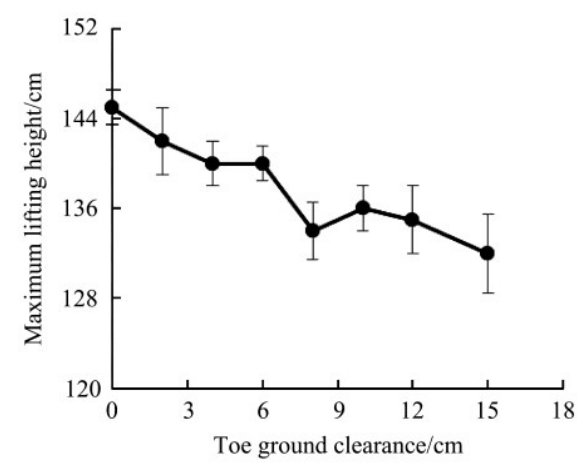

Note: FS was $2 \mathrm{~km} / \mathrm{h}$; RS was $110 \mathrm{r} / \mathrm{min}$.

Figure 7 Relationship between the toe ground clearance and maximum lifting height

\subsection{Orthogonal test}

In this section, the orthogonal test was carried out (three factors and three levels) to investigate the effect of the forward speed (A), the rotational speed of inside scrolls (B), and the toe ground clearance $(\mathrm{C})$ on the maximum lifting height. A total of nine test trials were conducted according to the orthogonal test design. The test results were shown in Table 4, which summarized the mean value of the maximum lifting height by repeating each group of trials 5 times.

\subsection{Range analysis}

The range analysis of orthogonal test results was carried out (Table 5). By calculating the mean maximum lifting height across one level of each factor, the relationship between the maximum lifting height and different factor levels was plotted in Figure 8.

As shown in Table 5, the range difference $R$ of each factor was calculated to $10.7 \mathrm{~cm}, 13.3 \mathrm{~cm}$, and $5.4 \mathrm{~cm}$, respectively. Comparing the magnitude of $\mathrm{R}$, the order of three factors affecting the maximum lifting height was obtained: $\mathrm{RS}>\mathrm{FS}>\mathrm{GC}$. The results of range analysis showed that the optimal combination was A2B2C1 (the forward speed was $2 \mathrm{~km} / \mathrm{h}$, the rotational speed of inside scrolls was $115 \mathrm{r} / \mathrm{min}$, and the toe ground clearance was $0 \mathrm{~cm})$. That was because, under this parameter setting, the maximum lifting height of the lodged sugarcane reached the optimum, which made the crop divider work more effectively.

Table 4 Results of orthogonal test

\begin{tabular}{ccccc}
\hline & \multicolumn{3}{c}{ Factors } & \multicolumn{2}{c}{$\begin{array}{c}\text { Maximum lifting height } h_{m} \\
\text { Number }\end{array}$} & A & B & C & 143 \\
\cline { 2 - 4 } & 1 & 1 & 1 & 145 \\
2 & 1 & 2 & 2 & 135 \\
3 & 1 & 3 & 3 & 150 \\
4 & 2 & 1 & 2 & 148 \\
5 & 2 & 2 & 3 & 142 \\
6 & 2 & 3 & 1 & 132 \\
7 & 3 & 1 & 3 & 150 \\
8 & 3 & 2 & 1 & 126 \\
9 & 3 & 3 & 2 & \\
\hline
\end{tabular}

Table 5 Range analysis of orthogonal test results

\begin{tabular}{cccc}
\hline & \multicolumn{3}{c}{ Factors } \\
\cline { 2 - 4 } & $\mathrm{A}$ & $\mathrm{B}$ & $\mathrm{C}$ \\
\hline$K_{1}$ & 423 & 425 & 435 \\
$K_{2}$ & 440 & 443 & 419 \\
$K_{3}$ & 408 & 403 & 425 \\
$k_{1}$ & 141.0 & 141.6 & 145.0 \\
$k_{2}$ & 146.7 & 147.6 & 139.6 \\
$k_{3}$ & 136.0 & 134.3 & 141.6 \\
$R$ & 10.7 & 13.3 & 5.4 \\
The better level & $\mathrm{A} 2$ & $\mathrm{~B} 2$ & $\mathrm{C} 1$ \\
\hline The order of three factors & & $\mathrm{B}>\mathrm{A}>\mathrm{C}$ & \\
affecting $h_{m}$ & & & \\
\hline
\end{tabular}

Note: $K_{i}^{j}$ is the sum of maximum lifting height at $i$-th level of factor $j, \mathrm{~cm}$, where, factor 1 is $\mathrm{FS}$, factor 2 is $\mathrm{RS}$, and factor 3 is $\mathrm{GC} ; k_{i}^{j}$ is the average maximum lifting height at $i$-th level of factor $j, \mathrm{~cm}, k_{i}^{j}=\frac{K_{i}^{j}}{3} ; R^{j}$ is the largest difference of the average maximum lifting height between the levels of factor $j$, $\mathrm{cm} ; h_{m}$ is the maximum lifting height, $\mathrm{cm}$.

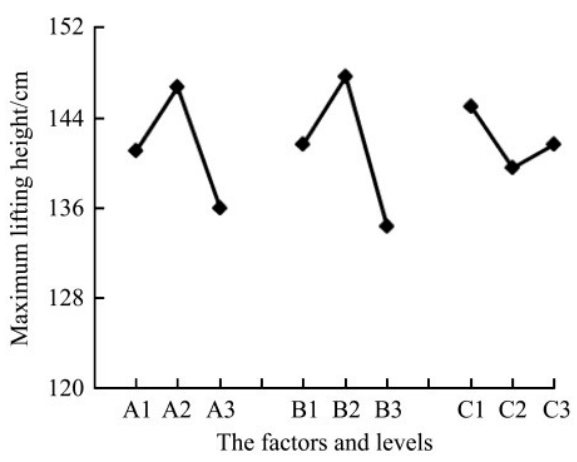

Figure 8 Comparison of the effect of each single test factor on maximum lifting height

The variation tendency of the indicator showed differences between the single factor tests and orthogonal tests. There may be an interaction effect between the influence factors. In future studies, the number of experimental groups to analyze the interaction effect between the factors will be increased. 


\section{Conclusions}

Based on the performance test of crop dividers of sugarcane chopper harvester, the harvesting test for severely lodged sugarcanes was carried on to evaluate the performance of crop dividers. The conclusions were as follows:

1) Through the single factor test, the optimum factor setting range of crop dividers was determined: forward speed (FS) was 2.0-4.0 $\mathrm{km} / \mathrm{h}$, rotational speed of inside scrolls (RS) was $100-$ $140 \mathrm{r} / \mathrm{min}$, and toe ground clearance $(\mathrm{GC})$ was $0-5 \mathrm{~cm}$.

2) The orthogonal test was conducted to obtain optimal factor-level combination: FS was $2.0 \mathrm{~km} / \mathrm{h}$, RS was $115 \mathrm{r} / \mathrm{min}$, and $\mathrm{GC}$ was $0 \mathrm{~cm}$.

3) By the range analysis, the order of each test factor affecting the maximum lifting height was obtained: $\mathrm{RS}>\mathrm{FS}>\mathrm{GC}$.

The test results can provide valuable references for the research and development of crop dividers of harvester. In the future, a controlling mechanism should be developed to adjust operation parameters of crop dividers adapting to the complex cane lodging conditions.

\section{Acknowledgements}

The research presented in this work was partially supported by the Major Program of the National Natural Science Foundation of China (Grant No. 32071916), the Major State Research Development Program of China (Grant No. 2016YFD0701200) and China Agricultural University, Institute for New Rural Development Guangxi Fusui Professor Workstation Grant (No. 201805510710115). Any opinions, findings, and conclusions expressed in this work are those of the authors and do not necessarily reflect the views of China Agricultural University. The authors acknowledge Mr. Xiangwei Li, Mr. Xiaobin Huang, Mr. Yuanmin Gan and Mr. Pingang Wu for their help in the harvesting test.

\section{[References]}

[1] Wei Z K. Status and existing problems of sugarcane harvesters. Farm Machinery, 2010; S3: 6-7. (in Chinese)

[2] Bai J, Ma S C, Huang X B, He S H, Wang F L, Xing H N. A comparison study on mechanized sugarcane production modes in China. ASABE Annual International Meeting, Boston, 2019; Paper No. 1900644. doi: 10.13031/aim.201900644.

[3] Fan Q J, Huang Q L, Wu H B, Zhou J C, Xie C, Wu T. Prospect and development of sugarcane mechanized harvest at home and abroad. Sugarcane and Canesugar, 2020; 49(6): 1-11. (in Chinese)
[4] Zhu X X. The discussion about developing full mechanization in China's sugarcane industry. Guangxi Agricultural Mechanization, 2010; 4: 11-14. (in Chinese)

[5] Ou Y G, Malcolm W, Yang D T, Liu Q T, Zheng D K, Wang M M, et al Mechanization technology: The key to sugarcane production in China. Int J Agric \& Biol Eng, 2013; 6(1): 1-27.

[6] Ma S C, Karkee M, Scharf P A, Zhang Q. Sugarcane harvester technology: a critical overview. Applied Engineering in Agriculture, 2014; 30(5): 727-739.

[7] Song C H, Ou Y G, Liu Q T. Design and experiment of two sections spiral sugarcane lifter for sugarcane harvester. Transactions of the CSAM 2012; 43(8): 89-93. (in Chinese)

[8] Song C H, Ou Y G, Liu Q T, Xie F X. Simulation and experiments of two-stage spiral sugarcane picking-up mechanism. Transactions of the CSAE, 2011; 27(5): 106-110. (in Chinese)

[9] Song C H. Mechanical analysis and experimental study for spiral sugarcane lifter. Journal of Hunan Agricultural University, 2017; 43(4): 460-463. (in Chinese)

[10] Xie F X, Ou Y G, Liu Q T. The whole stalk of sugarcane harvesters combined device kinematics of lifting. Journal of Agricultural Mechanization Research, 2009; 31(5): 27-30. (in Chinese)

[11] Xie F X, Ou Y G, Liu Q T. Experiment of combined-lifter device for sugarcane harvester. Transactions of the CSAM, 2011; 42(2): 94-98. (in Chinese)

[12] Gao J M, Ou Y G. Theoretical study on spiral sugarcane-lifting mechanism of sugarcane harvester and virtual prototype simulation. Transactions of the CSAE, 2004; 20(3): 1-5. (in Chinese)

[13] Zhang Y, Ou Y G, Mou X W. Virtual test on the finger-chain type sugarcane-lifter based on ADAMS. Transactions of the CSAE, 2009; 25(7): 88-93. (in Chinese)

[14] Dong Z, Meng Y G, Li Y M. Design of non-equidistant pitch sugarcane propping device. Journal of Agricultural Mechanization Research, 2010; 12(5): 79-84. (in Chinese)

[15] Mou X W, Xie F X, Ou Y G, Gong J. Experiments of lifting process for the lodged sugarcane. Journal of South China Agriculture University, 2010; 31(3): 98-101. (in Chinese)

[16] Li L, Xia P, Zhou X R. Experimental research and analysis on harvesting effect of whole-stalk sugarcane harvester. Journal of Agricultural Mechanization Research, 2014; 36(3): 174-177. (in Chinese)

[17] Liu Q T, Chen J K, Ou Y G. Spatial attitude of lodged sugarcane stalk in field. ASABE Annual International Meeting, Dallas, 2012; Paper No. 121341036. doi: 10.13031/2013.42040.

[18] GB/T 5262-2008. Standardization Administration of the PRC. Measuring methods for agricultural machinery testing conditions-general rules, 2008. (in Chinese)

[19] Bai J, Ma S C, Wang F L, Xing H N, Ma J Z, Wang M L. Performance of crop dividers with reference to harvesting lodged sugarcane. Sugar Tech, 2020; 22(5): 812-819.

[20] Song C H, Ou Y G, Liu Q T, Wang M M. Experimental study on influencing factors of lifting quality for push-over-type sugarcane harvester. Transactions of the CSAE, 2012; 28(16): 35-40. (in Chinese) 